\title{
Impact of job demands \& resources on burnout and engagement of railway employees in Mysore division
}

\author{
Raghavendra P. Kumar ${ }^{1, *}$, V. Murugaiah ${ }^{2}$ \\ ${ }^{1}$ Research Scholar, ${ }^{2}$ Professor, Institute of Management Studies, Davangere University, Davangere, Karnataka, India
}

*Corresponding Author:

Email: raghuhbk1988@gmail.com

\begin{abstract}
The primary objective of this study is to investigate the relationship between job demands with burnout and job resources with engagement. Primary data collected through face to face interaction by providing the structured questionnaire with five-point Likert scale is considered for rating. Secondary data obtained from journals, magazines, and internet. Overall 120 sample respondents chosen for the study. Group C and Group D employees are the targeted samples of the study.

Data is analyzed systematically by the correlation matrix and T-test of significance, the Correlation and pattern are calculated with the help of SPSS (22nd Version); T-test of relevance is calculated by using SmartPLS.

In this research paper, the findings are distinctive and integrated. JD-R model investigation shows there is a healthy relationship between the Job resource and engagement.

Researchers have found job demands are the causes of employees exhaust and cynicism, whereas the increase in the job resources of the organization will play a significant role in bringing the positive attitude of the employees. Physical and emotional demands are the critical factors affecting the employees. The JD-R model is a framework that can be used for Indian railways to reduce the job demands and increase the job resources, simultaneously to improve the personality of the employees and get the desired outcome.
\end{abstract}

Keywords: Job demands, Job resources, Burnout, Engagement, Employees, and Organization

\section{Introduction}

We can observe the two critical facets of the workplace, job demands and job resources. Bakker A.B (2011) is one of the great contributors to the study of job demands and resources related to employee engagement or work engagement in the workplace, stating that job performance is predicted by the work engagement and also identified three critical differences where engagement is constant. Work engagement is different from job satisfaction; engagement is different from the work-related flow and works commissioned from motivation (Schrott, L, Moosbrugger. D \& Iwanowa. A, 2016). Where job satisfaction stands for employee well-being, excellent work, pleasure (dedication) with high activation (vigor, absorption), and work-related flow refer to the most significant experience, motivation related to commitment (p.265).

Jose G and Mampilly S.R (2014), a high level of sense suggests that the participants would feel that their work and job happenings are meaningful and imperative. Bakker A.B and Demerouti E (2008) mentioned the performances of engaging workers are better than non-engaged workers. Engaged employees often experience positive emotions, including happiness, joy, and enthusiasm; experience better health; create their job and personal resources, and; transfer their engagement to others ( $p$ 215). It is important to know that job satisfaction, work-related flow and motivation are much needed for the work engagement to achieve the goal.

Work experience is having the significant influence on employee engagement. It is also perfect that the observed relationship between work experience and organizational commitment is not due to either age or grade of an employee, but independent of both of them (Mohapatra M and Sharma Baldev R, 2010). To perform better in the workplace organizations needs to motivate the employees who relate to the job satisfaction. This correspondence to Demerouti and Bakker (2011), job resources act as an extrinsic motivational role (p 2).

Wright and Cropanzano (2000) discussed fundamental proposition is 'happy' workers frequently perform well, and psychological well-being should be operationalized by 'happiness' (p. 91). Hakanen, Bakker, \& Schaufeli, (2006) said, an increase in the job, performance is possible only from reckoned employee engagement.

Demerouti et al. (2001) defined job demands as "those physical, social, or organizational aspects of the job that require sustained physical or mental effort and are therefore associated with certain physiological and psychological costs" (p. 501). Job resources were defined as "those physical, social, or organizational aspects of the job that may do any of the following: (a) be functional in achieving work goals; (b) reduce job demands and the associated physiological and psychological costs; (c) stimulate personal growth and development." (p. 501).

Robinson et al. (2004) define employee engagement as "a positive attitude held by the employee towards the organization and its value. An engaged employee is aware of the business context and works with colleagues to improve performance within 
the job for the benefit of the organization. The organization must work to develop and nurture engagement, which requires a two-way relationship between employer and employee."

\section{Literature Review}

Bakker A. B (2011) concluded. Work engagement predicts job resources and personal resources which lead to increase the job performance. Engaged employees dedicated to achieving the work-related goals with full of energy and absorbing the work carefully. Hence, employees and organizations work involvement is an essential indicator of occupational well-being. Thereby human resource managers have responsibilities to facilitate the suitable working conditions for the employee (p.268).

Salanovaa and Schaufeli, W. B (2008) discussed work engagement and job resources mediate the impact of job resources on proactive behavior at work and work engagement is very much related to growth and positively associated with active work behavior ( $\mathrm{p}$. 125).

Hakanen. J. J, Bakker. A.B and Schaufeli. W. B (2006), Cole. B (2014), Crawford.E.et al (2010), Rothmann and Joubert (2007), Hakanen. J.J, Schaufeli. W. B and Ahola. K (2008) found burnout and ill health is the outcomes of job demands, engagement and organizational commitment are the outcome of job resources, and burnout is negatively affected job resources. Similarly, burnout symptoms were negatively related to organizational commitment and positively associated with ill health, whereas engagement was positively associated with organizational commitment.

Schaufeli (2015), Cole B (2014), Crawford. E et al. (2010), Rothmann and Joubert (2007), discussed, the relationship of high job demands and reduced job resources is mediated by burnout (stress) and work engagement mediates the relationship between job resources and motivational process.

Demerouti et al.(2001): Coetzer \& Rothmann (2006): Hakanen et al (2008): Kinnunen et al (2011): Rodriguez-Muñoz et al (2012): Friedman (2014): found job demands such as time pressure, decision making process and long working hours cause for health impairment and job resources such as job control, social support from colleagues, and justice of the supervisor are acting as a motivator and leads to high level of engagement in the workplace.

Xonthoupoulu et al. (2007) find a significant relationship from job resources to personal resources, job resources to work engagement and job resources to work engagement (p. 132).

\section{Need for the study}

Meanwhile invention of JD-R model by Demerouti and her colleagues (Demerouti, Bakker, Nachreiner, \& Schaufeli, 2001), the Job Demands-Resources (JD-R) model has verified its utility as a miserly yet comprehensive model for conceptualizing and investigating occupational well-being, burnout, and engagement (Schaufeli \& Bakker, 2004).

The JD-R model, in both its new and improved forms (Bakker \& Demerouti, 2007; Bakker, Demerouti, \& Euwema, 2005), has been efficiently used in numerous contexts. These include research of burnout in hospital nurses (Demerouti et al., 2001), home care professionals (Bakker, Demerouti, Taris, Schaufeli, \& Schreurs, 2003), and call-centre workers (Lewig \& Dollard, 2003), as well as the study of repetitive strain injury and dedication in call-centre employees (Bakker, Demerouti, \& Schaufeli, 2003), engagement among dentists (Hakanen, Schaufeli, \& Ahola, 2008), the performance of human service professionals in various occupations (Bakker, Demerouti, \& Verbeke, 2004), A three-year cross-lagged study of burnout, depression, commitment, and work engagement (Hakanena J.J, Schaufeli W.B and Ahola. K. 2008), Dutch Teachers (Horn. J.E.V, Taris. W, Schaufeli. W.B and Schreurs. P.J.G, 2004).

From the available literature, the authors find a significant contribution in the field of Job demands and resources. Till now there are no research and evidence in the area of Job demands and supplies, Engagement and Burnout related to Indian Railways. However, present research article discovering the prominence of job demands and resources are the reasons for burnout and engagement. Hence this research paper is entitled 'Impact of Job Demands and Resources on Burnout and Engagement of Railway Employees in Mysore Division.'

\section{Objectives of the study}

The primary aim of this research is to investigate the relationship between the job demands and resources concerning burnout and engagement in the Mysore division. An attempt is made to know whether of job demands have the positive impact on exhaustion and adverse effects on employee engagement and also to know job resources have the adverse effect on burnout and positive impact on engagement.

\section{The rationale of the study}

Several studies have been previously conducted on the various factors affecting the employee engaged in multiple sectors including educational institutions. There is no evidence or proof of research activities conducted on Indian Railways. So, the authors have selected Indian Railways as a research area and identified the several job demands and resources in Indian railways which results in burnout and engagement.

In the earlier studies of engagement or JD-R model, it is coming to know that job demands have positively resulted in burnout and job resources are positively related to participation. The authors also 
identified the specific problems associated with the present research that, both job demands and job resources have the impact on employee engagement.

\section{Research methodology}

\section{Procedure and participants}

This study is evidence-based and empirical research in nature. Authors' have conducted the pilot survey, through the self-administered questionnaire. To ensure consistency (reliability), validity is measured before finalizing the questionnaire for the final study.

After identifying the employees and getting consent from the participants, researchers prepared the questionnaire which includes closed-ended questionnaire and face to face interaction method is used to collect the primary data (five-point Likert scale) from the employees. Secondary data are collected through various journals, textbooks, internet, newspapers, and magazines. The present study addresses the effect of job demands on burnout, and job resources on engagement.

Targeted Samples: Group C and Group D.

Group C employees perform at supervisory levels, such as Station Superintendents, Commercial Clerks, Reservation Clerks, Civil Engineers and Mechanical Engineers.

Group D employees perform at the lower level management such as Gateman, Pointsman, Khalasi, and Attendees.

\section{Measuring the variables \\ Burnout}

Burnout was assessed using the Maslach Burnout Inventory-General Survey (MBI-GS: Schaufeli et, al 1996). The instrument consisted of two sub-scales.

Exhaustion is measured with the seven items (e.g.,-I feel burned out from my work \& Working all day is a strain for me).

Cynicism is considered as an indifferent attitude of the employee toward work and is measured with five items (e.g., I have become less interested in my job). It includes five response options whereby $1=$ Strongly
Disagree to 5= Strongly Agree .

Engagement: Engagement was assessed using the UWES Questionnaire.

Vigor is measured with six items (e.g., I can continue working for a very long time), Absorption is measured with six elements (e.g., Time flies when I am working). Dedication is measured with five items (e.g., My job is challenging enough).

\section{Job demands}

The Workload is measured with seven items (e.g., I am unhappy with the night duty). Physical requirements are estimated with five elements (e.g., I am miserable to work in the remote area). Emotional demands are measured with nine items (e.g., There is high pressure from higher authority).

\section{Job resources}

Organizational resources are measured with the sixteen items (e.g., I am happy with the travel facilities provided to my family and me). Financial support is measured with the seven elements (e.g., I have an awareness of compensation benefits in my organizations). Supervisor support is measured by five pieces. (E.g., my supervisor paid attention to my level of competence). Autonomy is measured with six items. (I choose how to perform my work).

All the above statements include five options from $1=$ Strongly Disagree to $5=$ Strongly Agree .

\section{Tools and techniques used for data analysis}

The primary data obtained from the questionnaires and analyzed the content. General and straightforward statistical tools and techniques were used to analyze the data. The simple percentage is considered to explain the perception of employees on Job demands and resources. For qualitative data, researchers observed the content and reviewed the rating points. Investigation of the relationship between job demands and resources with burnout and engagement is capitalized through structural equation model by using of SmartPLS 3. 


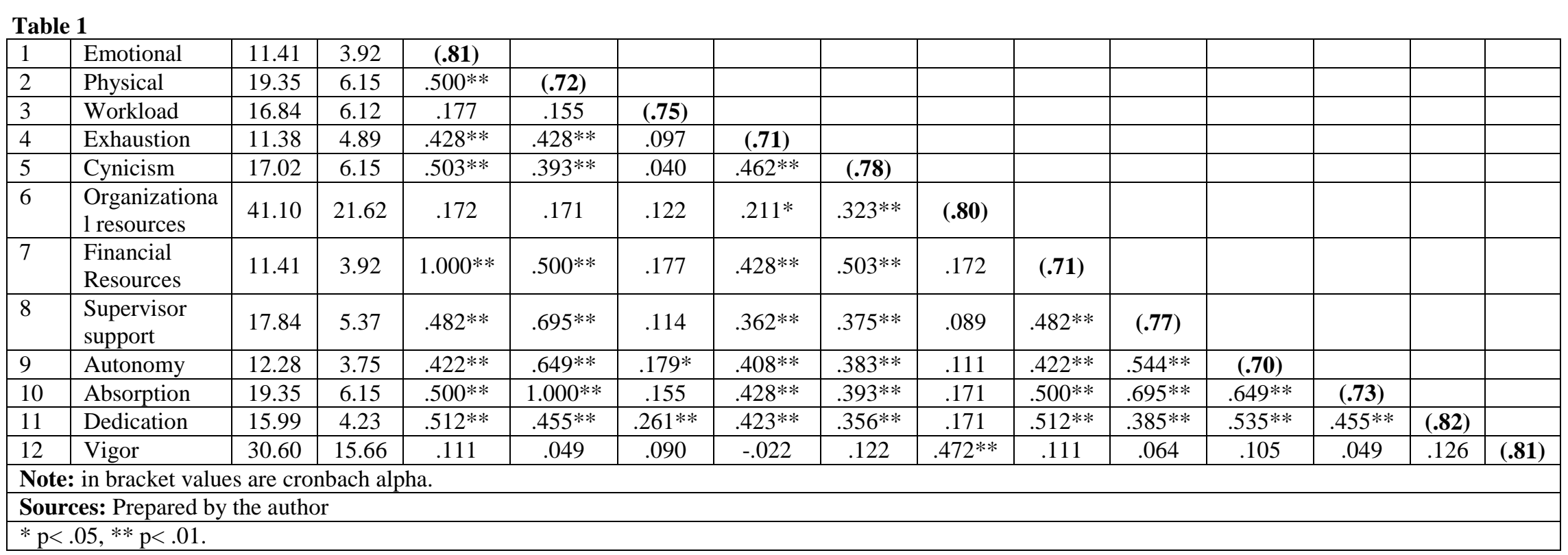




\section{Data analysis and interpretation}

Table-1 Correlation, Mean, Standard Deviations for Job demands, Job resources, Burnout, and Engagement Table-1 reveals, Mean, Standard deviation, correlation matrix, and values of Cronbach alpha for the observed variables of job demands, job resources, burnout, and engagement. All scales have profits of more than .70 and showed acceptable reliabilities.

Job demands> burnout: Emotional needs are significantly correlated with the exhaustion $(.428 * *)$ and cynicism $\left(.503^{* *}\right)$. Physical requirements are significantly associated with the exhaustion $(.428 * *)$ and cynicism (. 393**). The workload is not significantly correlated with the exhaustion (. 097) and cynicism (.040).

Job resources> engagement: Organizational resources are significantly correlated with the vigor $(.472 * *)$, and not significantly associated with the absorption (.171) and dedication (.171). Financial resources are significantly correlated with the absorption $(.500 * *)$, dedication $(.512 * *)$ and not significantly associated with the vigor (.111). Supervisor support is correlated substantially with absorption $\left(.695^{* *}\right)$, dedication $\left(.385^{* *}\right)$ and not significantly correlated with the vigor (.064). Autonomy is significantly associated with the absorption (. 649**), dedication (. 535**) and not significantly correlated with vigor (.105).

\section{Structural equation modelling}

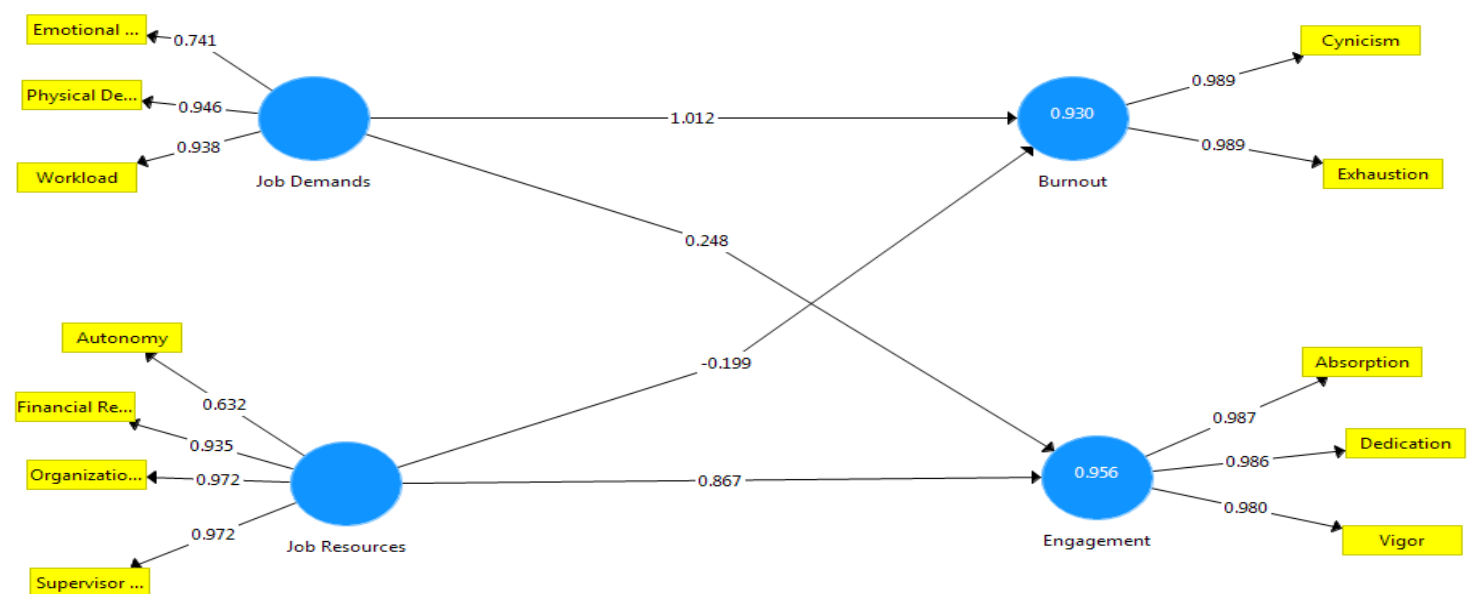

Source: Authors' calculations

Fig. 1: Job Demands-Resource Model, adopted from Bakker. A.B et al. (2004)

From Fig.1, Job demands, Job resource, Burnout, and Engagement are considered as latent variables. Observed variables for job demands are workload, physical demands, and emotional dem1nds, observed variables for job resources are organizational facilities, financial resources, autonomy and supervisors' support, observed variables for burnout are exhaustion and cynicism, and observed variables for engagement are vigor, dedication, and absorption (Taris T.W, Ybema J.F, and Beek I.V, 2017).

\section{Main findings}

Job demands are positively associated with the burnout, and the value is 1.012. Job demands are having a moderate positive association with the engagement, and the value is 0.248 . Job resources are positively associated with the engagement, and the value is 0.867 . Job resources are negatively associated with the (Cole. B, 2014: Crawford. E. et al. 2010: Reardon. S.F, 2010) with the burnout, and the value is -0.199 .

\section{Bootstrapping values exhibit the following results:}

Job demands $>$ Burnout $=$ Original sample is 1.012 , sample mean is 1.010 , standard deviation is 0.021 , TStatistics $=48.230$ and $\mathrm{P}$-value is. 000 .

Job demands $>$ Engagement $=$ Original sample is 0.248 , sample mean is 0.247 , standard deviation is 0.027 , TStatistics= 9.293 and P-value is. 000. If the job demands increase by one burnout will enhance up to 1.012. If the job demands increase by one engagement will enhance up to 0.248 .

Job resources $>$ Burnout $=$ Original sample is -0.199 , sample mean is -0.194 , standard deviation is -0.028 , TStatistics= 7.153 and P-value is. 000 .

Job resources $>$ Engagement $=$ Original sample is 0.867 , sample mean is 0.870 , standard deviation is 0.024 , T-Statistics $=35.853$ and $\mathrm{P}$-value is. 000. If job resources increases by one burnout will reduce in .0199. If job resources increases by one engagement will enhance to 0.867 . 


\section{Discussion}

Job demands have the positive impact on burnout. Employees are suffering more because of the physical demands. Job demands are the essential interpreters of burnout (Halbesleben 2010, Schaufeli \& Bakker 2004). After lengthy contact with high job demands, employees may frequently convert tired and manage the distance themselves psychologically from their work. In simple, they could jump to familiarity towards burnout (Bakker et al. 2000). The most critical job demands were role ambiguity, role conflict, role stress, stressful events, workload, and work pressure (Lee \& Ashforth 1996).

The negative relationship between emotionally demanding conditions and well-being of employees was explained by the health impairment process of the job demands-resources (JD-R) model (Bakker \& Demerouti, 2007). Consequently, emotionally demanding situations necessitate energy investment that would exhaust employees' resource pool. When energy is washed-out, job strain is likely to occur (Xontopoulu et al., 2013).

Job demands have the moderate positive association with engagement. According to the transaction theory of stress, individuals judge hectic circumstances such as job demands regarding their significance for comfort as either potentially inspiring or menacing (Lazarus \& Folkman, 1984).

Backup this perceptive, Cavanaugh et al. (2000) found dual causes, labeled challenge, and hindrance, underlying scores on items from several popular measures of stress. Examples of challenges that include in the workplace are demanded such as a high workload, time pressure, and high levels of job responsibility. Employees in the Mysore division have a habit of observing the job demands as chances to learn, accomplish, and prove the type of capability that tends to get award ad reward.

Job resources have the positive impact on engagement. Job resources are the most imperative analysts of work engagement (Halbesleben 2010, Schaufeli \& Bakker 2004). Christian et al. (2011) confirmed that job resources are the most important predictors of employee work engagement. The job resources found to predict work engagement were task variety, task significance, autonomy, feedback, social support from colleagues, a high-quality relationship with the supervisor, and transformational leadership.

In this study is found that job resources have the negative relationship with the burnout. In the job resources, organizational resources are the vital cog for employees working in Mysore division. It can be determined that particularly robust and reliable relationships with the available variables. Job resources are positively correlated with engagement (BabcockRoberson and Strickland, 2010), and job resources are negatively correlated (Cole.B, 2014: Crawford.E.et al 2010) to burn out.
Job demands are the reasons for employee burnout, and Job resources are the reasons to engage the employees in the workplace. Job resources will not allow the employees to burn out. In some cases job demands are going to be challenging in the workplace, this issue makes employees engage correctly to complete their responsibilities in the workplace.

Job resources have no power when job demands are too high (Demerouti and Bakker, 2011). An essential consideration in this research is employees cannot perform better in the evening and when energy resources are declining. Several job resources will overtake the job demands based on the job characteristics of the organization (Bakker, Demerouti, and Verbeke, 2004). Lawton R (1998) expressed time pressure, and the high workload is the two common reasons, where railway workers gave for noncompliance with safety rules were.

\section{Conclusion}

The present study disclosed that job demands and job resources are the two characteristics \& factors determining employee engagement. These two issues found almost in every organization, but dissimilar in the procedure. Demands and resources have distinctive possessions on burnout and engagement.

In the JD-R model job resources are considered as essential motivators and have the substantial Impact on engagement at work, whereas job demands have simulated effect engagement. A Gallup survey on employee engagement stated $87 \%$ of employees worldwide are not engaged. Various enterprises are feeling a crunch of engagement and aren't aware of it.

In the first stage of this study authors have found the unique perception of employees on job demands and job resources which are affecting the employee engagement. In the second stage, it is learned physical demands are having more impact on employee engagement, so job demands have the significant relationship with the burnout. In the third stage, job demands have the moderate positive association with the engagement because employees are considering the demands as challenging tasks in the workplace. In the fourth stage, it is observed job resources have strongly associated with the engagement, organizational resources are considered as the most critical factor to employees in Mysore division. Finally, job resources are negatively related to burnout which means employees are happy with the available resources in the Mysore division.

\section{Managerial implications}

Despite the limitations of the study, this article outcome has significant implications for future research and practices. Engaged employees continually associate with their work characters. Employee engagement can be calculated by the resources available in an organization and individual ability which results in 
lower turnover and improving the organizational performance.

To reduce the burnout organizations should reduce the specific job demands (workload, physical demands, and emotional demands). Global business managers can benefit the employees who facilitate the engagement at work. By using the JD-R model in this study, policies can be made to measure the employee engagement and find the drivers of employee engagement in different business sectors.

To learn and focus on interventions, it can be predicted and modified to improve the employee perception, develop the teams \& departments.

\section{Directions for future research}

Based on this study, further research can be able to conduct by considering the different welfare measures and challenging tasks for employees. A reasonable subsequent step would be to investigate the relationship of the engagement scales with other job-related welfare and demanding variables in the Indian Railways.

The convenience sampling method that was adopted in this study had included employees with different job titles and varied job accountabilities in the sample. Each of them perhaps had several levels of engagement and need of job resources. So, in future, a more homogeneous collection of respondents should be selected by aiming at either individual from a specific job description or those doing similar jobs.

\section{References}

1. Bakker A.B, Demerouti Evangelia and Verbek Willem (2004), Using the Job Demands-Resources Model to Predict Burnout and Performance, Human Resource Management, Spring 2004, Vol. 43, No. 1, Pp. 83-104

2. Bakker A.B, Demerouti Evangelia, and Euwema Martin. C (2005), Job Resources Buffer the Impact of Job Demands on Burnout, Journal of Occupational Health Psychology, Vol. 10, No. 2, 170-180.

3. Bakker A B, Emmerik Hetty Van, and Euwema Martin. C. (2006), Crossover of Burnout and Engagement in Work Teams, Work and Occupations, Vol 33, Issue 4, 2006

4. Bakker A B. Schaufeli W.B, Leiter Michael P, and Taris Toon W (2008), Work engagement: An emerging concept in occupational health psychology, Work \& Stress Vol. 22, No. 3, July-September.

5. Bakker A. B and Schaufeli W.B (2008), Positive organizational behavior: Engaged employees in flourishing organizations, Journal of Organizational Behavior. 29, 147-154.

6. Bakker A B. Demerouti Evangelia and Schaufeli W.B (2005), The crossover of burnout and work engagement among working couples, Human Relations, Volume 58(5): 661-689.

7. Bakker A B. and Demerouti Evangelia (2014), Job Demands-Resources Theory, Work, and Wellbeing: Wellbeing: A Complete Reference Guide, Volume III. Edited by Peter Y. Chen and Cary L. Cooper. John Wiley \& Sons, Ltd. Published by John Wiley \& Sons, Inc.

8. Brouwers André, Tomic Welko, Boluijt Huibrecht (2011), Job demands, Job control, Social support and Self-Efficacy Beliefs as Determinants of Burnout among
Physical Education Teachers, Europe's Journal of Psychology 1/2011, pp. 17-39

9. Barbier Marie, Hansez Isabelle, Chmiel Nik, and Demerouti Evangelia, (2012), Performance expectations, personal resources, and job resources: How do they predict work engagement? European Journal of Work and Organizational Psychology. 1-13, first article.

10. Barbier Marie, Dardenne Benoit, and Hansez Isabelle (2012), A longitudinal test of the Job Demands-Resources model using perceived stigma and social identity European Journal Of Work And Organizational Psychology. 1-15, first article.

11. Brauchli Rebecca, Jenny Gregor J, Füllemann Désirée, and Baueret Georg F. (2015), Towards a Job DemandsResources Health Model: Empirical Testing with Generalizable Indicators of Job Demands, Job Resources, and Comprehensive Health Outcomes, BioMed Research International Volume 2015 (2015), Article ID 959621, 12 pages.

12. Babcock-Roberson Meredith Elaine and Strickland O. J. (2010), The Relationship Between Charismatic Leadership, Work Engagement, and Organizational Citizenship Behaviors, The Journal of Psychology, 2010, 144(3), 313-326.

13. Cavanaugh, M. A., Boswell, W. R., Roehling, M. V., \& Boudreau, J. W. (2000). An empirical examination of self-reported work stress among U.S. managers. Journal of Applied Psychology, 85(1), 65-74. doi:10.1037/00219010.85.1.65

14. Cole Beatrix (2014), The relationship between job demands, job resources, engagement, burnout, and intention to quit, A Thesis for the degree of Master of Commerce (Human Resource Management) at Stellenbosch University.

15. Crawford. E, Lepine. J.A, Rich. B.L (2010), Linking Job Demands and Resources to Employee Engagement and Burnout: A Theoretical Extension and Meta-Analytic Test, The Journal of applied psychology. 95. 834-48. 10.1037/a0019364.

16. Ringle, Christian M., Wende, Sven, \& Becker, JanMichael. (2015). SmartPLS 3. Bönningstedt: SmartPLS. Retrieved from http://www.smartpls.com.

17. Demerouti E, Bakker A.B, Nachreiner F, Schaufeli W.B. (2001), The job demands-resources model of burnout, $\mathbf{J}$ Appl Psychol. 2001 Jun; 86 (3):499-512.

18. Demerouti Evangelia and Le Blanc Pascale M, Bakker A.B, Schaufeli W.B. and Hox Joop (2008), Present but Sick: A Three-wave Study on Job Demands, Presenteeism and Burnout, Career Development International Vol. 14 No. 1, 2009 pp. 50-68. Demerouti et al. (2001), Burnout and engagement at work as a function of demands and control, Scand J Work Environ Health 2001, Vol 27, no 4.

19. Friedman Gabriela (2014), Student Stress, Burnout and Engagement, A Thesis for the Master Degree in Organizational Psychology, University of Witwatersrand, Johannesburg.

20. Halbesleben, J. R. B. (2010). A meta-analysis of work engagement: Relationships with burnout, demands, resources, and consequences. In A. B. Bakker \& M. Leiter (Eds.), Work engagement: A handbook of essential theory and research (pp. 102-117). New York, NY: Psychology Press.

21. Hansez Isabelle and Chmiel Niki (2010), Safety Behavior: Job Demands, Job Resources, and Perceived Management Commitment to Safety, Journal of Occupational Health Psychology, Vol. 15, No. 3, 267278. 
22. Hakanen J.J. Bakker A.B and Schaufeli W.B. (2006), Burnout and Work Engagement among Teachers, Journal of School Psychology 43, 495-513.

23. Hakanen J.J, Schaufeli W.B. and Ahola Kirsi (2008), The Job Demands-Resources model: A three-year crosslagged study of burnout, depression, commitment, and work engagement, Work \& Stress Vol. 22, No. 3, 224241.

24. Jose G and Mampilly S.R (2014), Psychological Empowerment as a Predictor of Employee Engagement: An Empirical Attestation. Global Business Review 15(1) 93-104 @ 2014 IMI, DOI: 10.1177/0972150913515589, http://gbr.sagepub.com

25. Kinnunen Ulla, Feldt Taru, Siltaloppi Marjo and Sonnentag Sabine (2011), Job demands-resource model in the context of recovery: Testing recovery experiences as mediators, European Journal of Work and Organizational Psychology 1-28, first article.

26. Lazarus, R. S., \& Folkman, S. (1984). Stress, appraisal, and coping. New York, NY: Springer.

27. Mohapatra M and Sharma Baldev R (2010), Study of Employee Engagement and its Predictors in an Indian Public Sector Undertaking. Global Business Review, 11:2 (2010): 281-301. DOI: 10.1177/097215091001100210.

28. Macdonald Wendy (2003), The Impact of Job Demands and Workload on Stress and Fatigue, Australian Psychologist 38(2):102-117. DOI: 10.1080/00050060310001707107

29. Moura Daniel, Orgambídez-Ramos Alejandro and De Jesus Saul Neves (2015) Psychological Empowerment and Work Engagement as Predictors of Work Satisfaction: A Sample of Hotel Employees, Journal of Spatial and Organizational Dynamics, Volume III, Issue 2

30. Orgambídez-Ramos Alejandro, Alés Yolanda Borrego and Sierra María Isabel Mendoza (2014), Role Stress and Work Engagement as Antecedents of Job Satisfaction in Spanish Workers, Journal of Industrial Engineering and Management JIEM, - 7(1): 360-372.

31. Pradhan Gyanaranjan, Pattnaik Anindita, Panda Subhrabhanu and Panda Bhuputra (2015), Occupational Health Challenges of Railway Employees in India Towards Developing a Comprehensive Framework for Action, International Journal of Emergency Mental Health and Human Resilience, Vol. 17, No.2, pp. 514520.

32. Reardon. S.F (2016), School Segregation and Racial Academic Achievement Gaps, The Russell Sage Foundation Journal of the Social Sciences, 2(5), 34-57 (2016).

33. Rodriguez-Muñoz Alfredo Sanz-Verge Ana I. Demerouti Evangelia and Bakker A.B (2012), Reciprocal Relationships between Job Demands, Job Resources, and Recovery Opportunities, Journal of Personnel Psychology 2012; Vol. 11(2):86-94.

34. Salanova Marisa, Agut S, and Peiró J.M. (2005) Linking Organizational Resources and Work Engagement to Employee Performance and Customer Loyalty: The Mediation of Service Climate, Journal of Applied Psychology, Vol. 90, No. 6, 1217-1227, DOI: 10.1037/0021-9010.90.6.1217.

35. Sonnentag, S. (2003), Recovery, work engagement, and proactive behavior: A new look at the interface between non-work and work. Journal of Applied Psychology, 88, 518-528.

36. Salminen S.R, Mäkikangas Anne and Feldt Taru (2014), Job Resources and Work Engagement: Optimism as Moderator among Finnish Managers, Journal of European
Psychology Students. 5(1), pp .69-77. DOI: http://doi.org/10.5334/jeps.bu

37. Schaufeli W. B. and Bakker A.B (2004), Job demands, Job resources, and their relationship with Burnout and Engagement: A Multi-sample Study, Journal of Organizational Behavior 25, 293-315. DOI: 10.1002/job. 248 .

38. Schaufeli. W. B. and Bakker. A.B (2010), Defining and Measuring Work Engagement: Bringing clarity to the concept. Work engagement: A handbook of essential theory and research, (pp. 10-24).

39. Schaufeli W. B. Bakker A.B and Rhenen W. V (2009), How changes in job demands and resources, predict burnout, work engagement, and sickness absenteeism, Journal of Organizational Behavior, 30, 893-917 DOI: 10.1002/job.595.

40. Schrott, L, Moosbrugger. D \& Iwanowa. A, (2016), Applied Economics and Finance Vol. 3, No. 2. ISSN 2332-7294, E-ISSN 2332-7308

41. Taris T.W, Ybema J.F, and Beek I.V (2017), Burnout and engagement: Identical twins or close relatives? Burnout Research, Volume 5, June 2017, Pages 3-11.

42. Thirapatsakun Thanawatdech, Kuntonbutr Chanongkorn and Mechinda Panisa (2014), The Relationships among Job Demands, Work Engagement, and Turnover Intentions in the Multiple Groups of Different Levels of Perceived Organizational Supports, Universal Journal of Management 2 (7): 272-285, 2014.

43. Tadic Maja, Bakker A.B and Oerlemans Wido G. M. (2015), Challenge versus hindrance job demands and wellbeing: A Diary Study on the Moderating Role of Job Resources, Journal of Occupational and Organizational Psychology, 88, 702-725.

44. Tims, M, and Bakker. A.B. (2010), Job is crafting: Towards a new model of individual job redesign, SA Journal of Industrial Psychology, 36 (2), Art. \#841, nine pages. DOI: 10.4102/sajip. v36i2. 841

45. Tims M, Bakker A.B and Derks Daantje (2012), Daily job crafting and the self-efficacy - performance relationship, Journal of Managerial Psychology, Vol. 29 No. 5, 2pp. 490-507

46. Ugwu O F (2013), Work Engagement in Nigeria: Adaptation of The Utrecht Work Engagement Scale for Nigerian Samples, International Journal of Multidisciplinary Academic Research Vol. 1, No. 3,

47. Warren Samantha (2002), Show Me How It Feels To Work Here: Using Photography To Research, Organizational Aesthetics, Ephemera, Vol 2 (3): 224- 245

48. Wani S K (2013), Job Stress and Its Impact on Employee Motivation: A Study of a Select Commercial Bank, International Journal of Business and Management Invention Volume 2 Issue 3 Pp.13-18.

49. Xanthopoulou D, Bakker A.B, Demerouti Evangelia, Schaufeli W. B (2009), Reciprocal relationships between job resources, personal resources, and work engagement, Journal of Vocational Behavior 74, 235-244.

50. Xanthopoulu. D Bakker. A. B and Fischbach (2013), Work Engagement Among Employees Facing Emotional Demands- The Role of Personal Resources, Journal of Personnel Psychology, 2013; Vol. 12 (2): 74-84

51. Yener Müjdelen and Coşkun Özgün (2013), Using Job Resources and Job Demands in Predicting Burnout, Social and Behavioral Sciences 99 (2013) 869 - 876.

52. https://testbook.com/blog/15-reasons-indian-railways-isthe-best-employer/

53. https://en.wikipedia.org/wiki/Job_demandsresources_model

54. https://en.wikipedia.org/wiki/Work_engagement 
55. http://www.academia.edu/23885029/Defining_and_meas uring_work_engagement_Bringing_clarity_to_the_conce $\mathrm{pt}$

56. https://en.wikipedia.org/wiki/Occupational_stress

57. https://testbook.com/blog/15-reasons-indian-railways-isthe-best-employer/

58. https://en.wikipedia.org/wiki/Positive_psychology_in_the _workplace

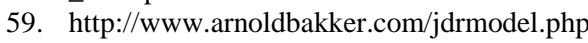

60. http://indiatoday.intoday.in/education/story/indianrailways/1/882519.html 